\title{
QUESTIONAMENTOS E PROPOSTAS SOBRE CORPOS DE EMERGÊNCIA: REFLEXÕES SOBRE INVESTIGAÇÃO ARTÍSTICA RADICALMENTE QUALITATIVA
}

\author{
Questions and proposals on emergency bodies: \\ reflections on radical qualitative artistic inquiry \\ Marília Velardi ${ }^{1}$ \\ Universidade de São Paulo
}

Resumo: Neste artigo a proposta é suscitar reflexões iniciais, mais do que trazer respostas, que nos conduzam a pensar coletivamente sobre o que almejamos quando procuramos alicerces para as pesquisas no campo das Artes. Ao nos assentarmos sobre métodos previamente estabelecidos, ainda que cunhados no campo das Artes, nós assumimos não apenas um modo de fazer, mas especialmente modos de ser e pensar. Como pensamos? Como queremos pensar?

Palavras-chave: Pesquisa artística; Investigação baseada nas artes; Epistemologias artísticas.

Abstract: In this article the proposal is to raise initial reflections, rather than bring answers, that lead us to think collectively about what we aim for when we look for foundations for research in the field of the Arts. By relying on previously established methods, although coined in the field of the Arts, we assume not only a way of doing, but especially modes of being and thinking. How do we think? How do we want to think?

Keywords: Artistic research; Arts based inquiry; Artistics epistemologies. ${ }^{1}$ Programa de Pós-Graduação em Mudança Social e Participação Política da Escola de Artes, Ciências e Humanidades
da Universidade de São Paulo.

Revista Moringa - Artes do Espetáculo, João Pessoa, UFPB, v. 9 n. 1, jan/jun 2018, p. 43 a 54

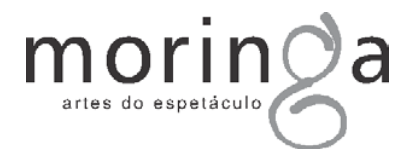


Temos buscado modos de pesquisar em Artes. Como pessoas do tempo presente, imersas nos programas de pós-graduação nas Universidades brasileiras, temos nos deparado com modos de investigação que exigem posturas e métodos acadêmicos capazes de garantir que a nossa pesquisa se vinculará à seriedade e à confiabilidade garantidas pelas fórmulas consagradas de fazer Ciência. Ao mesmo tempo, não é incomum que os estudos sobre as pesquisas acadêmicas nas Artes resvalem em reflexões sobre o quanto se distanciam ou devem se distanciar das pesquisas científicas e tecnológicas.

Há inúmeros textos e discursos nos quais as comparações e distanciamentos são traçados e parece que aquilo o que motiva os escritos critica a hegemonia do modo de fazer pesquisa acadêmica do tipo que outorga valor ou desvalor àquilo que tradicionalmente se faz como processo investigativo nas Artes. Isso leva muitas pessoas que escrevem sobre as pesquisas em Artes a buscarem os motivos pelos quais a pesquisa artística é, geralmente, colocada à margem dos estudos considerados relevantes ou essenciais para a Universidade moderna.

Os critérios científicos de validade interna e externa não nos cabem.

Não formulamos hipóteses a priori.

Estamos demasiadamente mergulhadas em nossos contextos.

Precisamos pensar em formular um conjunto de métodos de pesquisas cunhadas no campo das Artes.

Essa última afirmação tem guiado muitos estudos que, por sua vez, orientam modos e métodos que operacionalizam as pesquisas em Artes na Academia. Para tomar exemplos, recorro a duas expressivas formulações dentre algumas surgidas nos últimos 30 anos no campo das pesquisas nas Artes, e que estão organizadas em dois movimentos, ambos os quais bastante proclamados na Europa: a Pesquisa Artística e a Pesquisa baseada na Prática.

Um dos importantes pesquisadores responsáveis pela primeira proposta é Henk Borgdorff, professor de Teoria da Pesquisa nas Artes e pesquisador da Universidade de Leiden, na Holanda onde, segundo afirmam, os artistas são estimulados a fazerem pesquisa dentro e através da prática artística. As suas reflexões e posicionamentos redundaram na criação de disciplinas voltadas para a Teoria e Prática de Pesquisa em Artes na universidade onde leciona e também noutras, em centros da Finlândia, Reino Unido, Canadá, Austrália e África do Sul (BORGDORFF, 2017).

As questões postas pelo pesquisador não são completamente diversas de muitas das quais nos movem aqui, nos espaços acadêmicos brasileiros. Para o autor, pesquisar nas Artes e sobre as Artes deve ter o mesmo valor e, além disso, para ele não parece ser possível pensar num único método para a pesquisa artística. No entanto, deve-se considerar que o conhecimento artístico seria acessado pela pesquisa artística. Nas suas reflexões e posicionamentos consta:

A relação comum entre prática artística e reflexão teórica é que ambas se relacionam ao mundo existente. Mas o conhecimento artístico também está sempre incorporado em forma e matéria. Todos os processos criativos, práticas artísticas e obras de arte incorporam conhecimento que simultaneamente dá forma e expande os horizontes do mundo existente - não discursivamente, mas de maneira auditiva, visual e tátil, esteticamente, expressivamente e 
emotivamente. Esse "conhecimento artístico" é o objeto, além de ser parcialmente o resultado, da pesquisa artística conforme a definição proposta aqui. No debate sobre a pesquisa nas artes, há um desacordo sobre o que ou até aonde os produtos artísticos da pesquisa (as obras de arte concretas e práticas geradas pela investigação) devem ser discursivamente abordados - ou seja, acompanhados de uma contextualização, um aporte teórico, uma interpretação ou a reconstrução da documentação gerada no processo de investigação. Esse é um dos tópicos que demarcam 0 debate fundacional. Defendo que a translação discursiva é necessária.[...] Renunciar a isso implicaria em um desligamento com a academia. As formas discursivas nas quais essas abordagens podem ser feitas são altamente variáveis. Elas não se confinam ao discurso acadêmico convencional. (BORGDORFF, 2017, p. 318)

Pergunta o autor: até que ponto esta forma de pesquisa difere da pesquisa científica? E como isso se relaciona com o campo, com a Arte e com a prática? Há acadêmicos que defendem que as Artes e as Ciências, embora talvez próximas em alguns pontos da história, ainda permaneçam dois domínios e práticas fundamentalmente diferentes e, portanto, seria altamente inapropriado juntá-las numa única estrutura de ensino superior e de pesquisa.

Noutro texto o pesquisador já apontava para o fato de que, no que se refere à Academia, parece haver oposições desnecessárias entre pesquisa acadêmica, científica e artística, considerados por ele domínios e tradições essenciais da atividade humana que são institucional, teórica e historicamente segregados. Para ele o campo emergente da pesquisa artística permitiria que os domínios da
Arte e da Academia se encontrassem e se entrecruzassem (BORGDORFF, 2012).

A discussão proposta por Borgdorff - e veiculada com sucesso em diversas universidades na Europa, Nova Zelândia e Austrália - foi iniciada na esteira do processo de Bolonha. Antes disso, ele afirma, não havia pesquisa em todas as escolas de Arte ou conservatórios na Holanda, seu país de origem, mas com as mudanças na política em torno do ensino superior e do processo de Bolonha, a pesquisa foi subitamente colocada na agenda (WILSON, 2016).

As questões colocadas pelo autor transitam pela reflexão crítica e pela necessidade propositiva de instauração de grupos de investigação, disciplinas e políticas de publicação e financiamento das pesquisas artísticas nas Universidades europeias. E aqui eu acredito que precisamos parar e pensar, a despeito da pertinência e da profundidade das reflexões, críticas e proposições e do quanto estas se relacionam às questões que nós, pessoas pesquisadoras das Universidades brasileiras no campo das Artes, nos colocamos. É possível nos ampararmos nas considerações que fundamentam as propostas de Borgdorff para encontrarmos formas possíveis de investigarmos aquilo 0 que fazemos? Nomearmos a nossa pesquisa como artística e utilizarmos os mesmos métodos usados por ele como forma de proceder seria suficiente para fazermos o mesmo tipo de pesquisa proposta pelo autor? Contextos diversos, origens distintas... a Ciência nos diz que o bom método permite reprodutibilidade. Aqui, ou na Holanda... adequa-se, funciona. Se adequaria, funcionaria. Sim. Não? 
Neste ponto eu me recordo de algumas considerações feitas já há algum tempo pelo professor uruguaio Ernesto Spinak, pesquisador de processos de mediação e de avaliação de sistemas de informação científicas: "Se, como alguns acreditam, atividades científicas só podem se desenvolver dentro dos paradigmas escolhidos pelos países ricos, a consequência é que os países da América Latina são relegados ao status de colônias científicas." (SPINAK, 1996, p. 353, tradução nossa).

Não se trata de negarmos as considerações feitas por pesquisadores europeus, mas é preciso que contextualizemos o tempo e as circunstâncias que determinaram o método como forma de pensamento, as proposições e tomadas de decisão sobre as formas de investigação, antes de adotarmos aqui o método apenas como forma de ação.

No ano de 2006, Brad Haseman escreveu um artigo denominado $A$ Manifesto for Performative Research, texto discutido inclusive aqui no Brasil. Professor e pesquisador do curso de Práticas Criativas na Universidade de Brisbaine, na Austrália, a proposta de Haseman partiu de uma crítica ao que ele denominou paradigmas em pesquisa. Segundo eles os dois paradigmas hegemônicos seriam o quantitativo, orientado por métodos dedutivos e o qualitativo, definido, por sua vez, por métodos indutivos e ambos estariam de certo modo esgotados quanto às suas possibilidades de investigação nas Artes. Para ele um terceiro paradigma emergia no campo das Artes, dada a necessidade de superação dos outros dois, orientando uma pesquisa que denominou performativa.

Longe de propor uma crítica contundente e pormenorizada ao manifesto de Haseman, eu, no entanto, ouso questionar a sua reflexão sobre noção de paradigma e o quanto essa ideia pode não ser tão explicativa quanto se propõe. Primeiro porque não parece haver forte sustentação quanto à classificação de qualitativo e quantitativo como paradigmas em si, depois, porque não parece que as considerações feitas são suficientemente aprofundadas a ponto de darem conta da miríade de pesquisas e tipos de investigação que podem ser organizadas sob estes dois sombreiros. Na sua proposta da pesquisa performativa há o anúncio de um possível novo paradigma que, surgido e fundamentado nas Artes, fosse para além dela e, quiçá, cumprindo o papel de um paradigma científico, pudesse orientar olhares noutras áreas, como toda a indústria criativa e cultural em geral. A ideia de generalização e extrapolação do conhecimento parece ser algo a se considerar (HASEMAN, 2006).

A preocupação com as pesquisas nas Artes não se esgota nesses dois autores nem nas suas duas proposições guarda-chuva. Pesquisa baseada nas Artes, Pesquisa dirigida pelas Artes, Pesquisa orientada pelas Artes, e por aí seguimos...

Nas citações que eu trouxe até aqui a tradição disciplinar chama-me atenção: há, nesses movimentos - legítimos e críticos - a discussão sobre o que deve-não-deve configurar-se como princípio para as pesquisas, pensando nas Artes como campo disciplinar. Não podemos negar, no entanto, que talvez aqui possa haver o germe de um conflito: a proposição de uma pesquisa disciplinar, tradicionalmente e por excelência, é científica: é assim! Então, será que não estamos diante de um paradoxo? Ao pensarmos sobre como seria o nosso fazer pesquisa nesse campo disciplinar, buscando ou propondo a adoção de um modo autônomo e independente de fundarmos as nossas

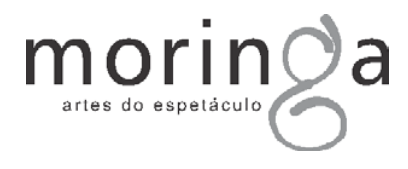


epistemologias, paradigmas, ou a nossa forma particular de fazermos pesquisa, nós não estamos pensando como as Ciências clássicas e disciplinares?

Não seria o caso de, ao invés de buscarmos um modo específico de investigar por aqui, como um tipo de pesquisa que atendesse à lógica disciplinar, nós nos abríssemos para a ideia de fluidez entre métodos, de bricolages, de métodos sem métodos? Não podemos pensar na validação de formas investigativas construídas por pessoas artistas pesquisadoras que, sabendo o que a academia pode favorecer e não só oferecer, tragam as suas propostas para que sejam construídos percursos investigativos e métodos singulares para as suas pesquisas interdisciplinares, multidisciplinares ou transdisciplinares?

Mas onde toda essa ideia poderia se alicerçar?

Parece que cursos superiores em Artes ainda carecem de lugar definitivo na Universidade brasileira: não é incomum surgirem ruídos e burburinhos sobre a sua exclusão. Ao mesmo tempo, a pesquisa acadêmica não parece ser unanimidade na formação de licenciados e bacharéis. Na pós-graduação, por sua vez, os órgãos de fomento às pesquisas alegam não dispor de recursos suficientes para o volume de programas nas mais diversas áreas. Some-se a isso a visão (quase senso comum) de que a prioridade no fomento deva voltar-se para as pesquisas científicas e tecnológicas, o que leva, sazonalmente, ao surgimento de temerários discursos sobre o fim das Artes e Humanidades como áreas acadêmicas e de pesquisa. Além disso, os modelos dos programas de pósgraduação são prioritariamente disciplinares $\mathrm{e}$ os programas interdisciplinares que podem abarcar pesquisas artísticas de modo inter, multi e transdisciplinar estão, neste momento, sob ataque e, após o golpe de 2016, as situações e perspectivas mostram-se ainda mais complexas.

No caso das ciências sociais e humanas, o produtivismo amparado pelas avaliações da CAPES se materializa numa miríade de efeitos preocupantes, alguns deles inesperados. Não me refiro apenas à precarização do trabalho de professores e estudantes ou à perda de organicidade da produção intelectual decorrente da ênfase obsessiva na escrita de artigos e de apresentações para congressos. Talvez o aspecto mais assustador e menos criticado de uma avaliação da pós-graduação inspirada pela ideologia produtivista seja que ela ampara 0 epistemicídio. O epistemicídio - noção desenvolvida, entre outros, por Boaventura de Sousa Santos consiste na eliminação ou inferiorização ativa de algumas formas de conhecimento em favor de outras, consideradas mais desejáveis no marco de uma dada estratégia de poder. Por exemplo, a anulação de certos saberes locais, sua folclorização ou deslegitimação pública foi e é uma modalidade de epistemicídio aplicada sobre diversas populações ao longo das experiências coloniais na América, África e Ásia. O produtivismo está a serviço do epistemicídio porque bloqueia ou dificulta seriamente e emergência de outras formas de construção e enunciação do conhecimento em um momento de relativa democratização das universidades públicas brasileiras. Em poucas palavras, o produtivismo compromete a diversidade das formas de fazer ciência e a própria criatividade humana no exato momento em que se converte em critério valorativo hegemônico para a distribuição dos recursos necessários à produção de conhecimento. Ao erigir-se como critério chave de avaliação da relevância da produção intelectual, ele impõe sistemas de hierarquização que só fazem reiterar privilégios epistêmicos de longa data e 
comutá-los, logicamente, em privilégios político-institucionais (MORAES, 2014, $\mathrm{s} / \mathrm{p})$.

Procuramos modos e métodos que operacionalizem a pesquisa em Artes, mas, antes disso, é preciso nos darmos conta de que método é, antes de tudo, forma de pensamento. Adotar um método deveria significar estudarmos os estudos dos métodos: metodologias (etimologicamente compreendida como os estudos sobre os caminhos para investigar). Ou seja, estudarmos os modos como os métodos foram construídos e identificarmos se como pensamos e agimos está intrinsecamente relacionado àquele método que optamos por utilizar. Para isso seria fundamental nos indagarmos: como nós pensamos, como o nosso pensamentos sobre as coisas foi construído e se construindo ao longo da nossa biografia? Sabemos sobre isso ou somos impelidas a formular problemas, objetivos e delimitarmos objetos antes mesmo de sabermos como pensamos sobre o que vemos, vivemos e lemos? Nós sabemos como pensamos quando pensamos em escolher métodos como forma de proceder e de fazer acontecer a pesquisa que faremos?

Pensamos dedutivamente, indutivamente, hipotético-dedutivamente, fenomenologicamente, hemeneuticamente (...)? Há modos distintos para pensamos sobre coisas diferentes. Sabemos disso. Sim, mas sabemos disso quando fazemos pesquisa?

Como pensamos sobre a vida da carne e a encarnação na pesquisa acadêmica, por exemplo? Atuando na e atuando a pesquisa e estando presente, presentificando a experiência vivida, encarnada. Esse é um modo.
Como eu penso quando estou aqui à frente do computador, organizando este artigo? Esse é o melhor modo de pensar sobre o que eu sinto ou pressinto? Ou apenas reproduzo códigos e normas estabelecidas sobre o que eu devo fazer? Seguir normas e códigos é uma escolha coerente com o modo como eu penso, ou é tão somente resposta à imposição?

Como penso quando eu me proponho a rememorar um processo ou experiência que vivi? Como EU penso? Como dizem para eu pensar? Rompo ou aceito? E quando penso, observo e descrevo um processo artístico ou pedagógico que estou (vi)vendo, como descrevo e escrevo? Atuo na escrita? Permito erigir uma escrita atuada, performática? Ou atuo conforme as regras de escrita do tipo: nunca em primeira pessoa, seja impessoal!

Pensando desses modos, o que é possível? Ver? Enxergar? Compreender? Analisar? Narrar? Sintetizar? Repare, o verbo vem depois: a ação é consequência... o objetivo da ação é consequência do pensamento. Mas e o pensamento? Muitas vezes vem depois da imersão, da vida, da experiência corporificada, vivida ou encarnada. Sabemos disso. Sabemos?

Como organizaríamos a pesquisa se aceitássemos tudo isso? Quais seriam as partes do trabalho, dissertação, tese ou artigo? Como se relacionariam? Quais seriam os lugares da teoria, dos teóricos e dos outros estudos sobre a mesma temática?

Sílvia Rivera Cusicanqui, socióloga Ch'ixi, postula uma investigação como a sua identidade andina-europeia-boliviana: manchada, pintada, cheia de justaposições que não resultam em hibridismos, mas convivem, coexistem. Inspira-me a pensar em nós e naquilo que fazemos. Para ela nas escritas 
tradicionais usadas no discurso oficial $e$ acadêmico ainda persiste o controle colonial, uma forma de produção em que as palavras não designam, mas encobrem, e ao fazer isso o que produz é uma narrativa que explicita um registro imaginário (disfarçado de realidade?) permeado por eufemismos que encobrem a realidade ao invés de nomeá-la. Nesse sentido os discursos públicos são formas de não dizer e criam um intrincado jogo de dissociação entre a linguagem escrita pública e a privada (RIVERA CUSICANQUI, 2010).

$\mathrm{E}$ as exigências dos programas de pósgraduação, ancoradas nas pesquisas clássicas muitas vezes nos empurram para uma lógica apriorística: pense, mas saiba que é preciso:

pensar desse modo,

escrever daquela maneira, conhecer que a pesquisa do artista é diferente da pesquisa na Arte.

Definamos as áreas: o que é daqui, o que é de lá?

\section{Não esqueça}

de traçar claramente o objetivo, de delimitar o objeto,

de estabelecer as bases teóricas,

de propor algo que colabore com o desenvolvimento da área e do campo.

E não se olvide do modelo. $\mathrm{M} \mathrm{o} \mathrm{d} \mathrm{e} \mathrm{I} \mathrm{o}$. Modelar a experiência é a norma vital.

Forma prévia, pré-concebida. Encaixar. Encaixotar?

Para criar algo, refletiu Aristóteles, deve-se juntar forma (morphé) e matéria (hyle). $\mathrm{Na}$ história subsequente do pensamento ocidental, esse modelo hilemórfico da criação arraigou-se ainda mais, mas também se desequilibrou. A forma passou a ser vista como imposta por um agente com um determinado fim ou objetivo em mente sobre uma matéria passiva e inerte. (INGOLD, 2012, p. 26)

Essa citação é de Tim Ingold, um antropólogo autodenominado não-antropólogo, que segue:

Quero argumentar aqui que os debates contemporâneos em campos os mais diversos - da antropologia e arqueologia à história da arte e estudos da cultura material - continuam a reproduzir os pressupostos que subjazem ao modelo hilemórfico, ainda que tentem restaurar o equilíbrio entre seus termos. Meu objetivo final, por outro lado, é derrubar o próprio modelo, e substituí-lo por uma ontologia que dê primazia aos processos de formação ao invés do produto final, e aos fluxos e transformações dos materiais ao invés dos testados da matéria. Relembrando Klee, forma é morte; dar forma é vida. Em poucas palavras, meu objetivo é restaurar a vida num mundo que tem sido efetivamente morto nas palavras de teóricos para quem o caminho para a compreensão e para a empatia está "naquilo que as pessoas fazem com os objetos". (INGOLD, 2012, p. 26)

Nas pesquisas científicas clássicas o conceito de objeto é fundamental para a elaboração do estudo: o recorte, a definição focal daquilo que se quer investigar. Aquilo que, de fora e sob determinada perspectiva anunciada a priori, pode ser observado, analisado, compreendido, experimentado. No entanto, não é preciso mais do que um gesto para colocar uma certeza em xeque: "ninguna teoría, método, forma de análisis de datos, discurso, género o tradición goza de una afirmación universal y general, e, portanto tem ou o 'derecho' o privilegio, de conocimiento autorizado." (RICHARDSON, 2000, p. 928). 
Qual tipo de investigadoras nós seremos nessa lógica, na qual somos impelidas a estudar a partir de fragmentos de textos, de partituras, de discursos, de peças, de cenas, de experiências, de vivências, de partes, subdivisões e trechos separados em capítulos? Estamos em busca de focos e objetos para que possamos analisar, comparar, compreender e discutir recortes, pedaços e frações. $E$ isso tudo é denominado acadêmica e cientificamente "dado" da investigação e é aquilo que ajuda a analisar o objeto da pesquisa que, pela sua natureza, nos remete ao sentido original de algo estático, cortado, observável, compreensível, analisável, muitas vezes generalizável, sem vida, ou algo que perde a sua vida para dar-se à investigação, permitindo-se ser estudado "anatomicamente": came sem sangue.

Ainda que estejamos juntas dessas coisas, nós temos nos colocamos de fora das experiências e, daí, localizamos o "objeto", algo que é manipulável, observável, visto de fora, distinto do sujeito e deslocado da experiência. Quando estudamos as coisas colocando-nos de fora delas é possível adotarmos algumas perspectivas para o olhar, no entanto, quando tratamos de investigar as experiências nas quais nos localizamos, durante os nossos mergulhos, é possível escolhermos não olhar de fora. Sim, deve ser possível.

De fato, ao lidarmos com a ideia de que é possível fazermos pesquisa acadêmica sem a delimitação de objetos de estudo, sem hipóteses e conjecturas formuladas antes das descrições e interpretações, nós precisaremos nos responsabilizar pelo modo como pensamos e alicerçarmos isso noutras epistemologias. $\mathrm{Ou}$ ontologias. $\mathrm{E}$ assumir terá implicações epistemológicas e políticas. Exige posicionamento de enfrentamento dos modelos vigentes, econômica, política e academicamente instaurados.

Com Rivera Cusicanqui, nos inspiramos:
A aposta da autora nesse último capítulo, 0 qual lembra um manifesto, é a de gerar uma produção descolonizadora feita por meio de permanentes deslocamentos e posicionamentos frente às teorias críticas emergentes que, ainda quando visibilizam as alteridades na história e no presente, se recolocam epistemologicamente como novas figuras coloniais. Assim, para refletir sobre as práticas e discursos descolonizadores, Rivera chama a pensar a condição colonial como uma condiçãa de múltiplos paradoxos, nos quais existem sucessivos processos de recolonização e colonizações internas. [...] é preciso continuar pensando no colonialismo interno, já que as relações coloniais se mantêm vigentes nos pequenos espaços de produção de conhecimento. No campo intelectual isso é importante já que ainda produzindo conhecimento crítico ele se configura como legítimo em companhia de relações de poder e subordinação, por isso a autora chama a "responsabilidade coletiva de não contribuir a renovação dessa dominação". (LARA, 2013, p. 558)

Há modos distintos para pensarmos sobre coisas diferentes. E uma questão que podemos nos fazer quando pesquisamos e lemos as pesquisas no campo das Artes é: consideramos as pesquisas, seus métodos e normas como algo canônico e continuamos vindo até a Academia para pensarmos a partir dos métodos científicos consagrados, ou pensamos multidisciplinarmente, transdisciplinarmente, artisticamente, criativamente, teatralmente, musicalmente, cinematicamente, dancisticamente - como nos desafia o ator, professor e acadêmico Johnnny Saldaña? (SALDAÑA, 2015).

Aqui me encontro nas proposições da pesquisadora Elizabeth St. Pierre, quando ela

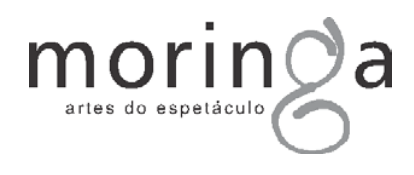


afirma quão necessário é rompermos com o hábito de corrermos para metodologias de pesquisa preexistentes e, ao invés disso, seguirmos as provocações que vêm de toda parte no desafio que é viver e escrever. As pesquisas qualitativas geradas na escola de Chicago de Sociologia já nas primeiras décadas do século vinte descolaram-se do modelo disciplinar e se deslocaram para as pessoas que fazem as pesquisas. A chamada terceira geração das pesquisas qualitativas norteamericanas assume que, mais importante do que a disciplina a qual a pesquisadora está vinculada, é essencial que quem faz pesquisa seja uma pessoa comprometida não só com uma área, mas com o campo da investigação, suas histórias e contextos. E nessa perspectiva, ser do campo, estar mergulhada nele e saber quem se é como pessoa e pesquisadora desse/nesse campo é uma exigência, uma necessidade, uma responsabilidade radical (ST.PIERRE, 2017).

Essas reflexões aparecem num tempo em que persiste $e$ segue fundamental $o$ questionamento sobre os lugares de fala, especialmente sobre quando alguém está falando por outro alguém. É pertinente também nos colocarmos diante da crítica sobre a ausência das histórias humanas contadas nas pesquisas como experiências e não como fragmentos. Um tempo em que precisamos resgatar a importância das contações de histórias a partir do ponto de vista da pessoa pesquisadora, que também é sujeita às experiências que narra. $\mathrm{E}$ que pensa, reflete, critica, revê, rememora, desdobra o que viveu enquanto conta para si as suas histórias. É, também, uma posição colocada para valorizar as ausências e os silêncios daquelas pessoas que não teriam direito à voz caso não falassem por si.

Essas reflexões também nos colocam frente à perspectiva de como os diários de campo, os cadernos de artistas, as anotações dos processos e intuições que thes atravessam , assim como as imagens fora de foco, os vídeos com ruídos, as conversas fora de hora são, algumas vezes, mais interessantes do que os relatórios produzidos. $\mathrm{E}$ isso marca uma posição contrária à crença de que os discursos sensíveis e impressões afetivas levam à perda da objetividade ou seriedade da pesquisa.

Há, na atualidade, inúmeros discursos e práticas investigativas que nos permitem compreender que quando despertamos para o fato de que é possível nos basearmos naquilo que vivemos como cerne da nossa organização e produção, nós podemos perceber que já sabemos algo. $E$ que não chegamos assim tão cruas em relação a nossa capacidade de construir pesquisa.

As pessoas artistas sabem da riqueza dos processos, do quanto envolvem de ordenação seguida de caos, seguida de ordenação... e de caos. De fluxo, fluência, estancamentos, paradas. Renúncias, descartes e incorporações. De como são alterados no percurso e do quanto, muitas vezes, estes são mais interessantes do que os resultados a da forma final. Cuidar dos percursos, valorizar os processos e narrá-los detalhadamente, erros e acertos: essa é talvez a mais importante premissa daquelas pessoas pesquisadoras que apostam os no fato de que as formas de investigação dentro e fora das Artes podem ser inspiradas por artistas em seus processos, e não só por epistemologias consagradas ou teoria a priori. Isso especialmente se a proposta 
for investigar experiências vivas, postas no mundo em movimento. E elaborarmos uma narrativa que seja coerente com isso tudo - e a trazermos para a Academia - parece mais do que uma tarefa, uma urgência. Para as Artes, mas também para a Ciência e a Tecnologia.

A despeito da digitalização, da globalização e das generalizações típicas do nosso tempo, é preciso encontrarmos caminhos particulares que nos permitam percursos e encontros locais, experiências construídas por pessoas que a presentificam, sob epistemologias criadas ali, com base naquilo que se é. Uma relação clara e assumida entre o transitório, o impermanente, o urgente, o imediato e a ancestralidade.

O resgate da experiência, a compreensão de que o pensamento ou a prática que ordenam a vida das pessoas comuns, das pessoas artistas, assim como os conhecimentos ancestrais - muitas vezes vítimas daquele já citado epistemicídio denunciado pelos estudos decoloniais - trazem, em si, a sabedoria que pode nos ajudar a organizar aquilo que queremos comunicar ou desvendar e que nos levaria, a partir daí, a fazer pesquisa acadêmica.

Nesse ponto acho interessante pensarmos sobre aquilo que a pesquisadora Elizabeth St. Pierre tem defendido: a investigação deve começar por um estranhamento sobre aquilo que nos é cotidiano, familiar e não necessariamente por uma pergunta, por um questionamento - o que tem sido o modo ordinário, aquilo que todos já fazem, a fórmula habitualmente consagrada. Pesquisar e escrever sobre o que investigamos é um chamado para um mergulho naquilo que, mesmo sendo familiar, nos oculta algo que poderá ser visto, caso seja contado. E isso nos pede que confiemos em algo inimaginável: que nós traremos à tona desse mergulho, afinal, um método de investigação e assim, criativamente, poderemos inventar e reinventar o mundo (ST. PIERRE, 2017b).

Nessa perspectiva somos, essencialmente, metodologistas. E para que isso se instaure é preciso que declaremos como nós pensamos, como nos organizamos, como tropeçamos, o que descartamos, como estamos fazendo para investigar e narrar ou comunicar ou trazer à tona aquilo o que investigamos. Contar para as pessoas como estamos fazendo, falar das idas e voltas, performar os diálogos e que estabelecemos, as linhas que traçamos, as malhas que tecemos.

Por esse caminho a pesquisa É Arte e seria, por assim dizer, uma pesquisa sobre método, sobre como pesquisar nas Artes. Na verdade, fazer pesquisa nessa perspectiva é contar histórias sobre como fizemos a nossa pesquisa. E para isso é preciso que encontremos quais elementos poderão nos ajudar e, como Norman Denzin já anunciou, assumirmos que:

Nuestras prácticas de investigación serão
performativas, pedagógicas y políticas. A
través de nuestra escritura y nuestra
charla, promulgamos el mundo que
estudiamos. Estas actuaciones son
desordenadas y pedagógicas. Ellas
enseñan a nuestros lectores acerca de
este mundo y cómo nos ven. Lo
pedagógico es siempre moral y político;
promulgando una forma de ver y de ser,
cuestiona, concursa, o hace suyas las
formas hegemónicas oficiales de ver y
representar el outro. (DENZIN, 2013, p.
212)

Eu estudo sobre investigações qualitativas: um espectro grande que se constrói a partir da lógica científica das Humanidades que vai, ao longo do tempo, passando por diversos campos e a partir da sua trajetória temporal relaciona-se

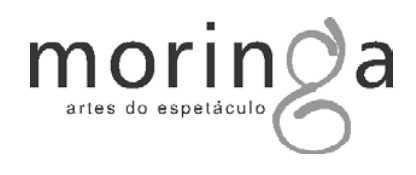


às situações e seus campos e vai se modificando. Eu aprendi a me inspirar na pesquisa qualitativa que surge a partir dos estudos da escola de Chicago de Sociologia, especialmente quando li os trabalhos de Charles Wright Mill, $A$ imaginação sociológica de 1959 e, antes dele, Robert Ezra Park, $A$ cidade e outros ensaios de ecologia urbana.

E essa pesquisa qualitativa que hoje está sendo conduzida por uma quarta geração de pesquisadores se alarga e, sob ataque da ditadura da Ciência e dos mecanismos neoliberais de patrulhamento da investigação acadêmica e artística, coloca-se na direção de pensar métodos que sejam não métodos. Fluidez. Pede-se fluxo na fluidez da investigação. Façamos aquilo que, como pessoas criadoras de formas de pensar 0 mundo, nos permita resgatar a humanidade nas pesquisas sobre as vidas e seus fluxos. Senão resgatar, radicalmente, instaurar.

Certas de que toda escolha de dados e de formas de análise é mais uma interpretação do que um olhar frio e distanciado da pessoa pesquisadora como entidade imparcial a serviço do avanço do conhecimento, é preciso que saibamos, crítica e conscientemente, como nós pensamos. Isso nos permitirá trazermos para a escrita acadêmica não apenas os dados que elucidam um problema de pesquisa e que foi estruturado na observação focal de um objeto ou campo super delimitado, ou as respostas às hipóteses (seriam conjecturas?); mas, que nos permitiria trazer aquilo que tradicionalmente foi considerado objeto e dado, desta feita, imersos e vivos nas histórias que podemos contar tendo-os como p r o t a g o $\mathrm{n}$ i s t a s. Perguntas, dados, objetos, hipóteses não são, necessariamente, os pontos da discussão, mas permitem que uma história seja contada.

Com Ron Pelias, professor de estudos da performance na Universidade Southern Illinois, inspiro-me a buscar uma forma de escritura que promulgue "um método do coração, uma forma que escute o coração, consciente de que as histórias são as verdades que não se aquietam" (PELIAS, 2004, p. 171, tradução nossa).

Sem vergonhas, sem medos, respaldadas por comunidades que criaremos e que nos ajudarão a trazer encarnação para as nossas divagações, alterando o tradicional critério de validade externa para o de representatividade e credibilidade: "meu caminho é o de volta para casa, de minha própria descoberta. Encontrar um modo de escrever que pareça eu mesmo escrevendo e não apenas alguém jogando jogos acadêmicos." (INGOLD, 2012, p. 10).

Aqui pensei em falar não sobre o que é, mas sobre o que pode vir a ser. Não sobre como deve ser, mas sobre como pode ser. Não apenas, mas também. Insurgências. Insubordinações. Transitoriedades. Impermanência.

Recebido em: 12/05/2018

Aceito em:29/05/2018

\section{Referências Bibliográficas}

BORGDORFF, H. O conflito das faculdades: sobre teoria, prática e pesquisa em academias profissionais de artes (tradução de Daniel Lemos Cerqueira). Opus, v. 23, n. 1, p. 314-323, abr. 2017.

BORGDORFF, H. The Conflict of the Faculties:

Perspectives on Artistic Research and 
Academia. Leiden University Press: Amsterdam, 2012.

BUTT, D. Artistic Research in the Future Academy. Intelect: Bristol, 2017.

DENZIN, N.K. Autoetnografía analítica o nuevo déjà vu. Astrolabio, [S.I.], n. 11, dic. 2013. ISSN 1668-7515. Disponível em: $<$ https://revistas.unc.edu.ar/index.php/astrolabio/ar ticle/view/6310/7398> (Acessado em 13/02/ 2017).

HASEMAN, B. A Manifesto for Performative Research. International Australia Incorporating Culture and Policy, theme issue "Practice-led Research” (no. 118): pp. 98-106, 2006.

INGOLD, T. Trazendo as coisas de volta à vida. Horizontes Antropológicos, Porto Alegre, ano 18, n. 37, pp. 25-44, jan/jun. 2012.

KORO-LJUNGBERG, M. Reconceptualizing qualitative research: methodologies without methodology, London: Sage, 2015.

LARA, A.E.M. RIVERA Cusicanqui, Silvia. Ch'ixinakax utxiwa: una reflexión sobre prácticas y discursos descolonizadores. Revista de Antropologia, São Paulo, USP, 2013, v. 56 no 2. pp. 597-604. Disponível em http://www.revistas.usp.br/ra/article/viewFile/8254 4/85519 > Acessado em 07/04/2018.

MORAES, A. Revistas Científicas ou túmulos do Saber? Outras Palavras: comunicação compartilhada e pós-capitalismo. 08/01/2014. Disponível em

$<$ https:/outraspalavras.net/posts/revistascientificas-ou-tumulos-do-saber/>. (Acessado em 7/01/2018).

PELIAS, R.J. A methodology of the heart: evoking academic and daily life. Walnut Creek: AltaMiraPress, 2004.
RICHARDSON, L. Writing: A method of inquiry. In: Denzin,N.K. \& Lincoln, Y. S. (Eds.). Handbook of Qualitative Research (pp. 923-948). Thousand Oaks, CA: Sage, 2000.

RIVERA CUSICANQUI, S. Ch'ixinakax utxiwa. Una reflexión sobre prácticas y discursos descolonizadores. Buenos Aires: Tinta Limón, 2010.

SALDAÑA, J. Thinking Qualitatively. London: Sage, 2015.

ST. PIERRE, E.A. Post Qualitative Inquiry: the next generation. In: DENZIN,N.K.; GIARDINA, M.D. Qualitative Inquiry in neoliberal times. pp. 37-47. New York: Routledge, 2017.

SPINAK E. Quantitative Analyses of Scientific Literature and their validity for judging Latin American production. Bulletin of PAHO. 1996; 29(4): 352-36. Disponível em $<\mathrm{http} / / / \mathrm{w} w \mathbf{w}$.scielo.edu.uy/scielo.php?script=sci_nl inks\&pid=S2393-

$6606201700020004900005 \& \operatorname{lng}=e n>$. Acessado em 09/05/2018.

ST. PIERRE. E.A. Writing Post Qualitative Inquiry. Qualitative Inquiry. Out/2017b, pp. 1-6. Disponível em: $<$ http://journals.sagepub.com/doi/pdf/10.1177/107 7800417734567>. Acessado em 24/03/2018.

WILSON, J. Artistic Research: in conversation with Henk Borgdorff. NiTRO (publication of The Australian Council of Deans and Directors of Creative Arts), on-line, 2016. $<$ https://nitro.edu.au/articles/edition-2/artisticresearch-in-conversation-with-henk-borgdorff>. Acessado em 17/05/2018. 